\title{
Multi-objective Design and Modeling of a Green Supply Chain GSC
}

\author{
El Hassani.H \\ Laboratoire LISER, ENSEM, Km 7 \\ BP 8118 Route El Jadida \\ Casablanca, Maroc
}

\author{
Benkachcha.S \\ Laboratoire LISER, ENSEM, Km 7 \\ BP 8118 Route El Jadida \\ Casablanca, Maroc
}

\author{
Benhra. J \\ Laboratoire LISER, ENSEM, Km 7 \\ BP 8118 Route El Jadida \\ Casablanca, Maroc
}

\begin{abstract}
The design of a sustainable supply chain involves consideration of social, economic and environmental objectives.

The social dimension is sometimes more difficult to identify or quantify in mathematical terms this is why in this work, the focus is on two objectives: economic (cost) and environmental (CO2 emissions).

This article discusses the design of supply chain management with consideration of carbon emissions in the total logistics costs by using a multi-objective model. Companies are more and more pushed to analyze their carbon emissions. This research is therefore concerned with them when they are due to transport and storage along the supply chain.

The objective is to compare the environmental criteria (carbon emissions) but also financial (stock level, mileage...).

The main objectives of the study are: to develop benchmarks for the simulation of supply chain and drive relevant experiences to optimize the green supply chains.
\end{abstract}

\section{Keywords}

Green Supply Chains, design, modeling of logistics networks, multi-objective formulation, environmental impact.

\section{INTRODUCTION}

Logistics plays a vital role in society by ensuring the provision of products and services to consumers while synchronizing the chain of supply and demand to meet.

Among its main resources, it uses the transport to liaise between the various links in the supply chain. But it is the subject of much criticism because of its negative impact on the environment. Having several definitions over the past decades, the so-called modern logistics is now understood as a planning function, execution and control of flows and stocks in the extended enterprise. It relies on the implementation of information and communication systems increasingly sophisticated and takes place in the Supply Chain defined by Mentzer [1] as "a set of three or more entities (companies or individuals) crossed by the upstream and downstream flows of products, services, information and finance from a supplier to a customer".

Traditionally, design models of supply chains determine the optimal configuration of all network facilities of the company for the supply of raw materials to final product delivery to the demand zone.

Directly affected by the rising price of fuel and energy sources used in air conditioning, refrigeration and heating, as well as congestion and deterioration of road infrastructure, companies are increasingly concerned about energy and environmental issues and are forced to rethink about their logistics in order to reduce their costs and increase their competitiveness. Conscious of their Image, sensitive to societal expectations and driven by new government regulations, many of them are also moving to control their greenhouse gas emissions. Added to this is the need to take in charge the returned goods and ensure the collection and recycling of end of life.

With the implementation of the Kyoto Protocol, industries suffer from environmental pressure which disrupts the way to build their network. Indeed, the regulations on greenhouse gas emissions, energy and natural resources consumption and the production of materials for the landfill causing companies to consider the environmental impact of their products while seeking to decrease it.

The life cycle analysis is a method of evaluating the potential environmental impacts associated to a product, process or activity. This method identifies and quantifies the energy and resources used and waste released into the environment, convert into $\mathrm{CO} 2$ equivalent, and finally associate to them environmental impacts or potential damage. It covers the entire life cycle of a product, from the extraction of raw materials through the transportation, distribution and recycling to finish at the disposal of the product at the end of life [2].

This paper is organized as follows: in section 2 a literature review and a historical are introduced, in section 3 the proposed approach is introduced; finally; in section 4, concluding remarks are outlined.

\section{LITERATURE REVIEW}

\subsection{Historical}

The study and management of industrial pollution was a key element into society since the early days of the industrial revolution. Part of the industrial revolution was motivated by the strategies of Adam Smith concerning the specialization of labor firms in particular and companies in general. This specialization increased the need to develop specific channels of suppliers and distribution [3].

Some of the earliest works that can be related to the 'greening' of the supply chain today are those of Ayres and Kneese [4].

Very promising prospects have been opened with the integration of competitive advantages and economic benefits of environmental practices among organizations later in the decade of the 80s [5].

More management, less technology, managing GSCM began in focusing on aspects of SCM such as logistics [6] and [7] purchase [8], and reverse logistics [9] and [10]. Some work 
has integrated purchasing, operations, marketing, logistics, and reverse logistics while focusing on the environment [11].

The first developments were mainly conceptual, introducing various concepts and practices related to GSCM. This area took then more maturity that allowed subsequent studies to move towards a theoretical development, and possibly empirical studies and use other advanced tools for formal modeling to assess GSCM [12].

There were many variations in the definition of GSCM and terminology over the years. The following list includes some of the terms characterizing this concept:

- Sustainable Management of logistics network [13] and [14];

- The sustainability of supply and demand in enterprise networks [13] and [15];

- Environmental management of the supply chain [16];

- Green purchasing [17] and supply [18];

- Green Logistics [19] and environmental logistics [20];

- Sustainable supply chains [21].

For several years, research has been conducted to develop decision models incorporating the principles of the analysis of life cycle and principles of designing supply chains resulting in the appearance of green supply chains.

The design of a green supply chain involves the addition to the traditional objective of minimizing costs, a second objective of minimizing the environmental impacts of products and companies processes [22].

Of course, the concept of compromise is introduced as well as the necessary investments for companies in new technologies to reduce emissions. The final result creates an efficiency curve showing all possible solutions obtained when combining the two objectives according to the degree of importance given to the one or the other functions to optimize [22].

The Regulations of limiting the impact of the design of supply chains on the environment is becoming increasingly fierce. This is why the design and modeling is one of the main concerns of businesses today [23].

Seuring and Muller [12] defined the sustainable management of the supply chain as materials, information and capital flows management, as well as cooperation between companies throughout the supply chain while taking into account the objectives of the three dimensions of sustainable development, namely economic, environmental and social, which are derived from customer and stakeholder requirements.

We adopt this definition and Fig. 1 shows such a framework that integrates the three dimensions of sustainable development: economic, social and environmental.

The optimization here is taken into account by reducing the total logistics cost and profit maximization in the various activities of the supply chain (purchasing, production, storage, distribution, recycling, etc.).

Environmental sustainability means that permanent environmental damage should not be allowed and the regulations relating to GHG emissions are implemented. The social dimension includes objectives such as reducing noise, congestion and stress and improve the level and quality of life in communities across the supply chain.

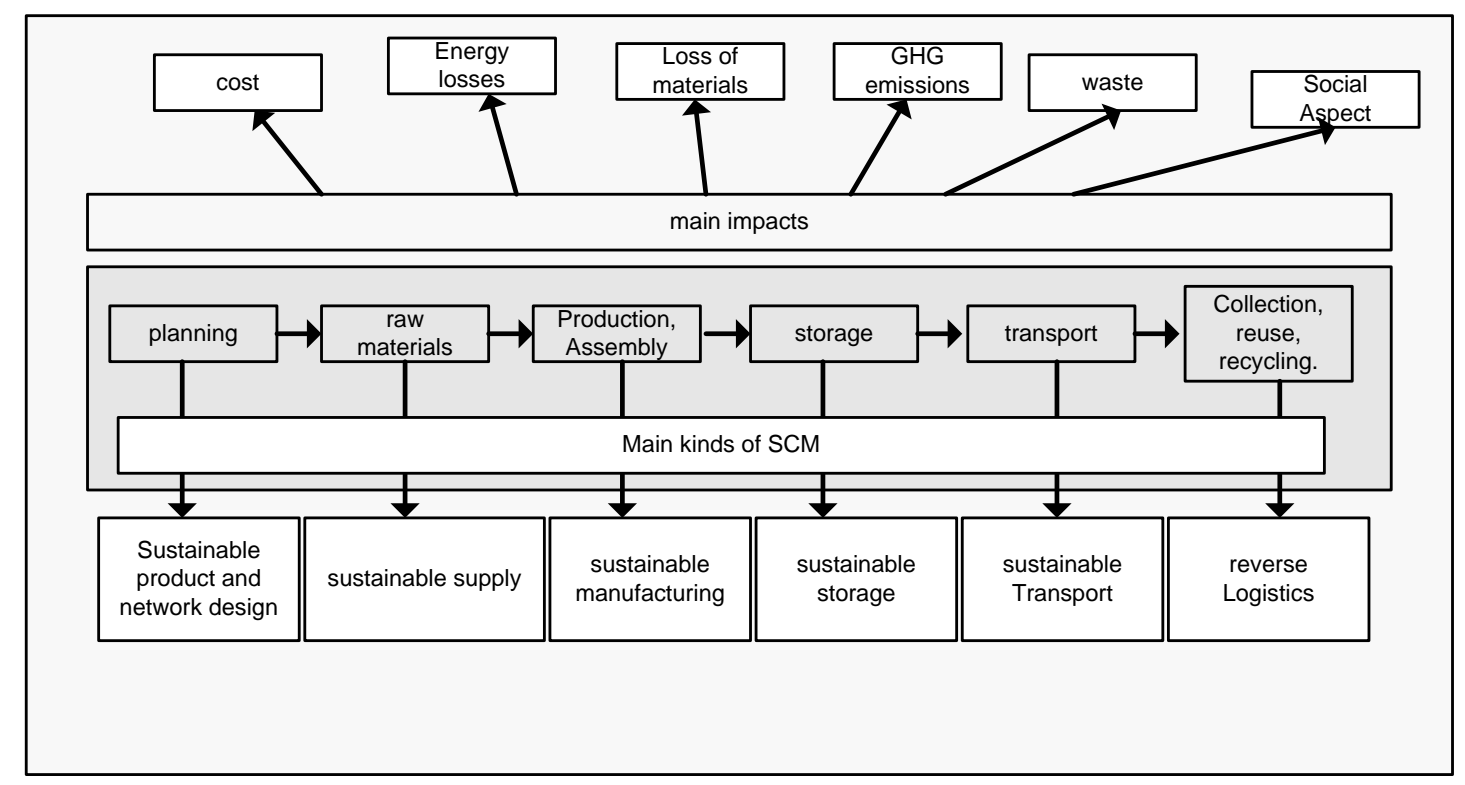

Fig 1: Key Concepts of Managing a green supply chain

The economic dimension of the design of the supply chain has been well studied, and the typical approach taken by most researchers and practitioners uses mathematical techniques pursuing programming optimization of a single objective function or multiple objective functions. The increase in regulatory legislation for carbon and waste management and joint development of the corporate social responsibility and citizenship means that companies must now pursue a multi- objective optimization (MOO) to find the best balance between often conflicting objectives [24].

Various studies were conducted on indicators for assessing the environmental performance of supply chains such as in [25], [26], [27] and [28]. In addition, [29] conducted an ecoefficiency analysis for the evaluation of this performance, and ranked the environmental impacts on the basis of five key aspects: consumption of raw materials, consumption of energy, emissions that result of those processes, potential 
toxicity, and the potential risk. In their study, they indicate that the three main factors are emissions and energy and raw material consumption (approximately 20\% each). In addition, among emissions, air emissions account for $50 \%$. For them, the $\mathrm{CO} 2$ greenhouse gas emissions, is the reference measurement. According to the Intergovernmental Panel on Climate Change (IPCC - GIEC), the main problem that the world must and will face is global warming due to the increase of $\mathrm{CO} 2[30]$.

The Kyoto Protocol came to quantify, at least for the signatory countries, those emissions in 1997.

The transport and storage count for $50 \%$ in its environmental impact relatively to the different activities in the supply chains [31] and [32].

Based on the literature mentioned above, this research therefore focuses on the integration of $\mathrm{CO} 2$ emissions mainly due to transport along a supply chain in the calculation of total costs.

\section{MATHEMATICAL MODEL}

\subsection{Problem and formulation:}

In what follows we will formulate the problem mathematically. Network in the following figure defines the elements of the model.

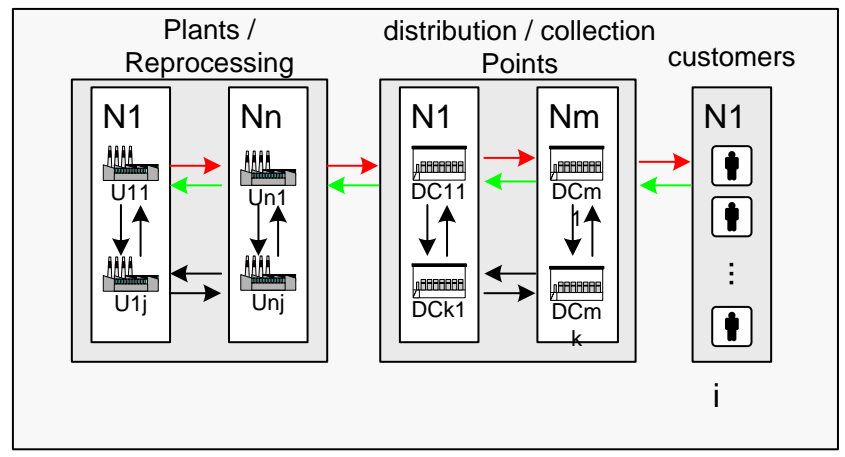

Fig 2: global representation of a SCM

The Demand of Product from customers is known in advance and deterministic. In the case of a direct flow (red), the supply chain consists of multi-level plants, distribution points and final customers. In the reverse channel (green) products at the end of their life cycle are taken from clients, and then sent to reprocessing plants through collection points at different levels. Products out of these plants can be introduced as new products in the direct chain to form a closed-loop chain.

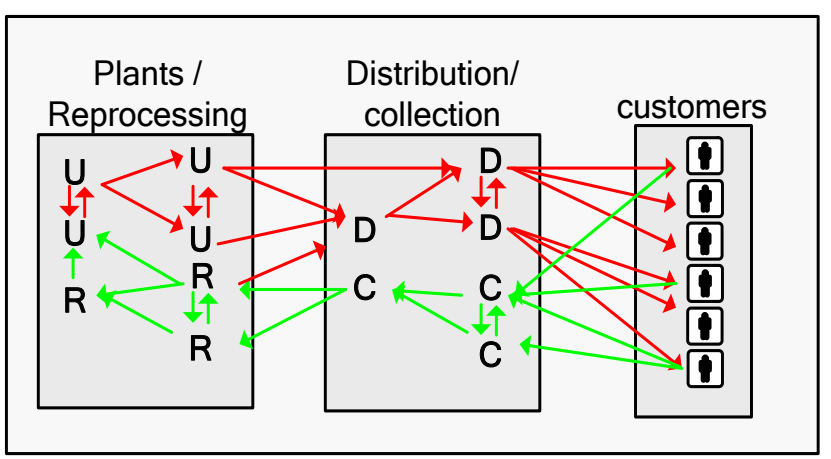

Fig 3: representation of flows in a green supply chain

\subsubsection{Localization Problem Study of CFLP problem}

The problem of locating facilities vary on:

(1) the nature of the information. A distinction is made,

a. Deterministic problems.

b. Stochastic problems.

(2) The capacity of facilities. A distinction is made, a. Problems of facilities localization with finite capacity (capacitated facility localization problem).

b. Problems of facilities localization infinite capacity (uncapacitated facility localization problem).

(3) The planning horizon. A distinction is made,

a. Problems of static localization (static facility localization problem)

b. The problems of dynamic localization (dynamic facility localization problem)

(4) the cost structure. A distinction is made,

a. Linear costs

b. Nonlinear costs.

(5) The number of objectives to be optimized. A distinction is made,

a. Localization issues mono-objective.

b. Localization issues multi-objective.

(6) the number of levels . A distinction is made,

a. The problems of single-level Localization.

b. The problems of multi-levels Localization.

The CFLP has a particular interest to us because it is the basis for the design of logistics networks. The models developed for the problem CFLP can be easily adapted to the study of other types of problems.

Products are sent from one company to another by ship, truck or plane or by combination of these three modes. To calculate the $\mathrm{CO} 2$ emissions, we must model the distance between the two companies and estimate the weight and bulk products. Emissions depend on the weight transported, the mode of transport used, the distance, and the size of storage. Indeed, the unit of $\mathrm{CO} 2$ emission is $\mathrm{g}$ or $\mathrm{kg}$ per $\mathrm{m}^{2}$ or tonne.km [33].

ASIF approach [34] consider gas emissions G in transport as a function of activity level (A) in $\mathrm{Km}$-passenger or $\mathrm{Km}$-tone in every transport mode, modal structure (S),fuel intensity in each mode (I) in liter per $\mathrm{Km}$-passenger or $\mathrm{Km}$-tone, and emission factor $(\mathrm{F})$ in gramme of carbon per liter of fuel consumption. All these parameters are represented in ASIF equation as follows:

\section{$\mathbf{G}=\mathbf{A} * \mathbf{S} * \mathbf{I} \mathbf{F}$}

Model: \{Deterministic, infinite capacity, static, linear cost, mono-objective, multi- echelon, 1 product $\}$.

The simple uncapacitated multi-echelon facility Location model (SUPW) [35].

In this model, the problem of multi-level location is treated. The facilities are spread over several levels.at each level $\mathrm{j}$ we have $n_{j}$ facilities responsible for supplying facilities $n_{j+1}$ of level $\mathrm{j}+1$. It is proposed to determine the facilities that will be opened at every level to meet customer demands while minimizing associated costs. 


\section{The global structure of the mathematical model [36] is:}

\section{Data:}

$\mathrm{c}_{\mathrm{ijk}}=$ cost of production and distribution of entire customer's order $\mathrm{k}$ if the order is made by the production site and $\mathrm{i}$ went through the warehouse $\mathrm{j}$.

$f_{i}=$ fixed cost of hiring the production site $i$ (in other words the installation i level 1).

$\mathrm{g}_{\mathrm{j}}=$ fixed cost of hiring the warehouse $\mathrm{j}$ (in other words the installation $\mathrm{j}$ level 2).

$\mathrm{I}=$ set of all production sites (facilities level 1)

$\mathrm{J}=$ set of all warehouses (level 2 facilities).

$\mathrm{K}=$ set of all customers.

\section{Decision variables:}

$\mathrm{x}_{\mathrm{ijk}}=$ proportion of customer $\mathrm{k}$ demand satisfied by the production site $\mathrm{i}$ and $\mathrm{j}$ warehouse.

$z_{i}=1$ if facilitie $i$ of Level 1 is opened.

$=0$ otherwise.

$\mathrm{y}_{\mathrm{j}}=1$ if facilitie $\mathrm{j}$ of Level 2 is opened.

$=0$ otherwise

Model:

Minimize $\sum_{i \in I} \sum_{j \in J} \sum_{k=K} c_{i j k} x_{i j k}+\sum_{i \in I} f_{i} z_{i}+\sum_{j \in J} g_{j} y_{j}$

Constraints:

$$
\begin{aligned}
& \sum_{i \in I} \sum_{j \in J} x_{i j k}=1, k \in K \\
& \sum_{j \in J} x_{i j k} \leq z_{i}, i \in I, k \in K \\
& \sum_{i \in I} x_{i j k} \leq y_{j}, j \in J, k \in K \\
& x_{i j k} \geq 0, i \in I, j \in J, k \in K \\
& z_{i} \in\{0,1\} i \in I ; y_{j} \in\{0,1\} j \in J
\end{aligned}
$$

The objective function minimizes the total cost of opening and acquiring facilities. The constraint (1) ensures that the demand of each customer is satisfied. Constraint (2) ensures that a customer is supplied only from an opened production site. Constraint (3) ensures that a customer is supplied only from an opened warehouse.

This model is a mixed integer linear program.

\subsubsection{Generalization to a problem of $N$ levels :} A proposed model of localization to $\mathrm{N}$ levels is formulated in [37] as follows:

data:

$\mathrm{P}=$ set of all possible paths $\mathrm{p}$. One possible path is a sequence of adjacent facilities to meet a proportion of the customer demand.

I (j) = set of all potential facility $i(j)$ of level $j$.

$\mathrm{J}=$ number of levels.

$\mathrm{K}=$ set of all customers.
$P_{i(j)}=$ set of all paths through the installation number $i$ to $j$-th level.

$\mathrm{c}_{\mathrm{pk}}=$ variable cost (production + distribution) associated with the supply of customer $\mathrm{k}$ by the path $\mathrm{p}$.

$f_{i(j)}=$ fixed cost of opening facility number $i$ of level $j$.

\section{Decision variables:}

$\mathrm{x}_{\mathrm{pk}}=$ proportion of customer $\mathrm{k}$ demand satisfied by path $\mathrm{p}$.

$\mathrm{z}_{\mathrm{i}(\mathrm{j})}=1$ if facility $\mathrm{i}(\mathrm{j})$ of level $\mathrm{j}$ is open.

$$
=0 \text { otherwise. }
$$

Model:

$$
\text { Minimize } \sum_{k \in K} \sum_{p \in P} c_{p k} x_{p k}+\sum_{j=1}^{J-1} \sum_{i(j) \in I(j)} f_{i(j)} z_{i(j)}
$$

\section{Constraints:}

$$
\begin{aligned}
& \sum_{p \in P} x_{p k}=1, k \in K \\
& x_{p k} \leq z_{i(j)}, p \in P_{i(j)}, k \in K, i(j) \in I(j), j \\
& =1,2,3 \ldots J-2, J-1 \\
& z_{i}(j) \in\{0,1\}, i(j) \in I(j), j=1,2,3 \ldots J-2, J-1 \\
& x_{p k} \geq 0, p \in P, k \in K
\end{aligned}
$$

The objective function minimizes the cost of acquiring and openness. The constraint (1) ensures that the demand of each customer is satisfied. Constraint (2) ensures that for each selected path, all the facilities are open, ensuring a customer is supplied only from opened facilities. Note that in the model presented above, we reasoned on the number of levels $\mathbf{J}$ and not on the number of steps $\mathrm{N}$. This choice is made to simplify the model and is justified by the relationship between the number of steps $\mathrm{N}$ is the number of levels $\mathrm{J}(\mathrm{J}=\mathrm{N}+1)$.

This model is a mixed integer linear program.

Figure below represents a problem of locating facilities in four levels (three steps). The bold green line represent the following path $\{3$ (1), 2 (2), 1 (3), 2 (4) \} that connects the facility number 3 level 1 , the facility number 2 Level 2 , the facility number 1 level 3 and customer number 2 level 4 .

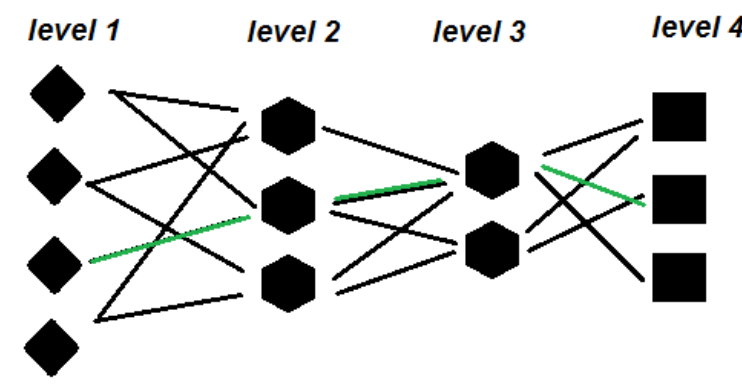

Fig 4: representation of a path (green line)

The present model is useful for problems of small sizes. However, for large problems, it becomes very cumbersome to implement because it requires the enumeration of all possible 
paths (see Fig 4) of the first level facilities to clients. Hence the use of meta-heuristics.

In this phase, some results on logistics optimization using genetic algorithm [38] will be very useful in coming exploration.

As an example of gene representation of this conception is given in Fig 5.

\begin{tabular}{|c|c|c|c|c|}
\hline leve/1 & leve/2 & \multicolumn{1}{c}{ leve/3 } & leve/4 & cost \\
\hline 3 & 2 & 1 & 2 & 200 \\
\hline
\end{tabular}

\section{Fig 5: gene representation}

\subsubsection{The multi-objective models}

According to [39], [40] and [41], the mulit-objective models proposed for dealing with the problem of locating facilities have a vector of objective functions instead of one, however, the constraints are similar to those previously detailed models. The great difficulty of multi-objective models is not in the formalization of the problem, but rather in solving the proposed model.

According to [24], there are two ways to solve a multiobjective problem:

(1) Method 1: it consists of the following steps: - Classification of the objectives (priority) - Assigning priority coefficients to the objectives (the more important the objective is, the greater priority coefficient is). The sum of the coefficients of all priority objectives is equal to

- Aggregation of objectives into a single function using the weighted sum of the objectives. - Determination of the optimal solution of the problem by considering the aggregate objective function.

(2) Method 2: it is to seek effective solutions (optimal in the sense of Pareto) of the problem.

To do this, the following steps are followed: - Assigning weight (priority coefficients) the objective functions to convert the multi-objective problem in a monoobjective problem.

- Determine the optimal solution of mono-objective problem.

- Check that the solution is effective or not (if the solution is dominated by another solution then it is not effective. If the solution is not dominated by any effective solutions, then it is effective).

- Vary the priority coefficients. - Repeat this procedure several times to get the most possible effective solutions.

It should be noted that in the case where the decision maker chooses to apply the method 2, a set of non-dominated solutions will be determined. A good approach is to apply a multi-decision method to all non-dominated solution to determine the best solutions.

\subsubsection{Transportation problem}

It was in 1941 that Frank L. Hitchcock made for the first time the transport problem, which is to minimize the total cost of transporting a shipment plan. Minimizing both the total distance and the cost of transportation is part of the theory of flow networks.

Formulation of the transport problem A transportation problem can be described as follows: A given amount of a uniform product is available at each of the origins (eg deposits). It is to send the amounts specified in each destination (eg distribution points). We know the cost of transporting a unit of a product from its origins to one of the destinations. Assuming that it is possible to ship products from any origin to any destination, it is to determine the minimum cost of transport origins to destination points.

We assume that there are $\mathrm{m}$ origins and $\mathrm{n}$ destinations. Variable $x_{i j}$ represent the number of shipped origin $i$ to destination $\mathrm{j}$ units. $\mathrm{x}_{\mathrm{ij}} \geq 0$ for all $\mathrm{i}, \mathrm{j}$. I for each original data, there are $n$ possible values of $j$, this implies that there are $(m \times n) x_{i j}$ different.

The linear problem is:

$$
\operatorname{Min} Z=\sum_{j=1}^{n} \sum_{i=1}^{m} c_{i j} x_{i j}
$$

Under the following constraints:

$$
\begin{gathered}
x_{i j} \geq 0 \quad i=1 \ldots . . m \text { et } j=1 \ldots . . n \\
\sum_{j=1}^{n} x_{i j}=a_{i} \quad i=1 \ldots \ldots m \\
\sum_{j=1}^{m} x_{i j}=b_{i} \quad j=1 \ldots \ldots n
\end{gathered}
$$

The total received by each destination is the sum of the amounts received from each origin. Needs of destinations are satisfied if :

$$
\sum_{j=1}^{n} b_{j=} \sum_{j=1}^{m} a_{i}
$$

\section{Global model Parameter:}

Possible Localization:

- $\quad$ plant / reprocessing $(n, j) \in(N, J)$

- $\quad$ distribution/collection $(\mathrm{m}, \mathrm{k}) \in(\mathrm{M}, \mathrm{K})$

- Customer i $\in$ I

\section{Implementation Costs:}

$\boldsymbol{I}_{\boldsymbol{j}}^{\boldsymbol{n}}$ Planting a plant / reprocessing site $(\mathrm{n}, \mathrm{j})$ costs.

$\boldsymbol{I}_{\boldsymbol{k}}^{\boldsymbol{m}}$ Implementation costs of a distribution point / collection site $(\mathrm{m}, \mathrm{k})$.

\section{Matrix decision of location:}

$\boldsymbol{X}_{\boldsymbol{j}}^{\boldsymbol{n}}$ Decision to set up a plant / reprocessing site (n, j) $1=$ yes

$0 \quad=\quad$ no.

$\boldsymbol{X}_{\boldsymbol{k}}^{\boldsymbol{m}}$ Location decision of a point of distribution / collection site $(\mathrm{m}, \mathrm{k}) 1=$ yes $0=$ no.

\section{Transportation cost:}

$\boldsymbol{T}_{j j}^{n n}$ transportation costs of the plant / reprocessing site (n, j) in the plant / reprocessing site $(n, j)$. 
$\boldsymbol{T}_{j \boldsymbol{k}}^{n m}$ transportation costs of the plant / reprocessing site (n, j) at the distribution / collection site (m, k).

$\boldsymbol{T}_{\boldsymbol{k} \boldsymbol{k}}^{\boldsymbol{m} \boldsymbol{m}}$ transportation costs from the point of distribution / collection site $(\mathrm{m}, \mathrm{k})$ at the point of distribution / collection site (m, $\quad \mathrm{k})$. $\boldsymbol{T}_{\boldsymbol{k} \boldsymbol{i}}^{\boldsymbol{m}}$ transportation costs from the point of distribution / collection site $(\mathrm{m}, \mathrm{k})$ to the client i. $\boldsymbol{T r}_{j j}^{n n}$ transportation costs of the plant / reprocessing site (n,j) at the plant / reprocessing site $(n, j)$.

$\boldsymbol{T r}_{\boldsymbol{j} \boldsymbol{k}}^{n \boldsymbol{n}}$ transportation costs from the point of distribution / collection site $(m, k)$ at the factory / reprocessing site (n, j).

$\boldsymbol{T r}_{\boldsymbol{k} \boldsymbol{k}}^{\boldsymbol{m} m}$ transportation costs from the point of distribution / collection site $(\mathrm{m}, \mathrm{k})$ at the point of distribution / collection site $(\mathrm{m}, \mathrm{k})$.

$\boldsymbol{T r}_{\boldsymbol{k} i}^{\boldsymbol{m}}$ transportation costs customer i at the distribution / collection site (m,

$\mathrm{k})$.

Product flow:

$\boldsymbol{F}_{\boldsymbol{j} \boldsymbol{j}}^{\boldsymbol{n} \boldsymbol{n}}$ product stream plant / reprocessing site $(\mathrm{n}, \mathrm{j})$ in the plant / reprocessing site $(\mathrm{n}, \mathrm{j})$.

$\boldsymbol{F}_{\boldsymbol{j} \boldsymbol{k}}^{\boldsymbol{n} m}$ product stream plant / reprocessing site $(\mathrm{n}, \mathrm{j})$ at the distribution / collection site (m, k). $\boldsymbol{F}_{\boldsymbol{k} \boldsymbol{k}}^{\boldsymbol{m} \boldsymbol{m}}$ product flow distribution point / collection site (m, k) at the point of distribution / collection site $(\mathrm{m}, \mathrm{k})$.

$\boldsymbol{F}_{\boldsymbol{k} \boldsymbol{i}}^{\boldsymbol{m}}$ flux product flow distribution point / collection site (m, k) to the client i. $\boldsymbol{F r}_{j \boldsymbol{j}}^{n \boldsymbol{n}}$ product stream plant / reprocessing site $(\mathrm{n}, \mathrm{j})$ at the factory / reprocessing site (n, j).

$\boldsymbol{F r}_{j k}^{n m}$ product flow distribution point / collection site (m, k) at the factory / reprocessing site (n, j). $\boldsymbol{F} \boldsymbol{r}_{\boldsymbol{k} \boldsymbol{k}}^{\boldsymbol{m} m}$ product flow distribution point / collection site (m, k) at the point of distribution / collection site $(\mathrm{m}, \mathrm{k})$.

$\boldsymbol{F r}_{\boldsymbol{k} \boldsymbol{i}}^{\boldsymbol{m}}$ product stream i customer at the point of distribution / collection site (m, k).

$\boldsymbol{\tau}_{\boldsymbol{i}}$ return rate of customer product $\mathrm{i}$.

$\boldsymbol{C}_{\boldsymbol{j}}^{\boldsymbol{n}}$ capacity plant or reprocessing plant located in (n, j).

D distance in $\mathrm{Km}$

Economic Objective (F 1)

Minimization of total implementation costs:

$$
\operatorname{Min} Z_{1}=\sum_{n, j \in N, J} I_{j}^{n} X_{j}^{n}+\sum_{m, k \in M, K} I_{k}^{m} X_{k}^{m}
$$

Minimization of total transportation cost (direct):

$$
\begin{aligned}
\operatorname{Min} Z_{2}=\sum_{n, j \in N, J} T_{j j}^{n n} F_{j j}^{n n}+ & \sum_{n, j \in N, J} T_{j k}^{n m} F_{j k}^{n m} \\
& +\sum_{m, k \in M, K} T_{k k}^{m m} F_{k k}^{m m}+\sum_{m, k \in M, K} T_{k i}^{m} F_{k i}^{m}
\end{aligned}
$$

Constraints:

Demand Constraints:

Total product Demand of customer i $=\sum_{m, k \in M, K} F_{k i}^{m} \forall i \epsilon I$

$$
\sum_{i \in I} F r_{k i}^{m}=\sum_{i \in I} \boldsymbol{\tau}_{\boldsymbol{i}} F_{k i}^{m} \quad \forall(m, k) \epsilon(M, K)
$$

Capacity limits of plant and reprocessing:

$$
\sum_{m, k \in M, K} F_{k j}^{m n} \leq C_{j}^{n} X_{j}^{n} \quad \forall(n, j) \epsilon(N, J)
$$

Regulation Constraints of direct and non direct flows :

$$
\begin{gathered}
\sum_{n, j \in N, J}\left(F_{j k}^{n m}+F r_{j k}^{n m}\right)=\sum_{i \in I} F_{k i}^{m} \quad \forall(m, k) \epsilon(M, K) \\
\sum_{i \in I} F_{k i}^{m}=\sum_{n, j \in N, J} F r_{k j}^{m n}
\end{gathered}
$$

UR :

Constraints of non-negativity :

$$
U R=\left\{\begin{array}{l}
U \\
R
\end{array}\right.
$$

$$
\begin{gathered}
F \geq 0 \text { et } F r \geq 0 \\
\forall(n, j) \epsilon(N, J) \quad \forall(m, k) \epsilon(M, K) \quad \forall i \epsilon I
\end{gathered}
$$

Binarity of decision matrix:

$$
X \in\{1,0\}
$$

\section{Environnemental Objective (F2):}

$$
\begin{gathered}
\operatorname{Min} Z_{3}=\sum F e * D * F l u x \\
\operatorname{Min} Z_{3}=\sum_{i \in I} \sum_{m, k \in M, K} D_{k i}^{m} F_{k i}^{m}+\sum_{i \in I} \sum_{m, k \in M, K} D_{k i}^{m} F_{k i}^{m} \\
+\sum_{\substack{n, j \in N, J \\
m, k \in M, K}} \sum_{k j}^{m n}\left(F r_{k j}^{m n}+F_{j k}^{n m}\right. \\
\left.+F r_{j k}^{n m}\right)
\end{gathered}
$$

This function transforms the energy and resources consumed during the transport activities in greenhouse gas emissions.

In this function $Z_{3}$ we can integrate the ASIF approach as well as we describe in the previous section of this paper.

\section{CONCLUSION}

Representing a key role in trade, logistics is a complex system composed of a multitude of actors and interrelationships between suppliers, manufacturers, logistics providers and distributors responsible for delivering the product and / or service to the final consumer at the best economic, social and environmental conditions.

In this article we discussed the design of supply chain within the environnemental impacts especially $\mathrm{CO} 2$ emissions by using a multi-objective model. this model will help us simulating this context using meta heuristic approaches 
(Genetic algorithm) tanking in consideration all presented constraints (the environmental and financial criteria...) to optimize the green supply chains.

\section{REFERENCES}

[1] MENTZER J. T. et al., Defining Supply Chain Management, Journal of Business Logistics, Vol. 22, $\mathrm{N}^{\circ} 2,2001$

[2] Chaabane, A., Ramudhin, A., Paquet, M. (2010) Design of sustainable supply chains under the emission trading scheme. International Journal of Production Economics, doi:10.1016/j.ijpe.2010.10.025

[3] Lun, Y.H.V., Lai, K.H., Wong, C.W.Y., Ng, C.T., Cheng, T.C.E., 2011. Research in shipping and transport logistics. International Journal of Shipping and Transport Logistics 3 (1), 1-5.

[4] Ayres, R.U., Kneese, A.V., 1969. Production, consumption, and externalities. The American Economic Review 59 (3), 282-297.

[5] Frosch, R.A., Gallopoulos, N.E., 1989. Strategies for manufacturing. Scientific American September, 144152

[6] Murphy, P.R., Poist, R.F., Braunschweig, C.D., 1994 Management of environmental issues in logistics: current status and future potential. Transportation Journal 34 (1), $48-56$.

[7] Szymankiewicz, J., 1993. Going green: the logistics dilemma. Logistics Information Management 6 (3), 3643.

[8] Drumwright, M.E., 1994. Socially responsible organisational buying: environmental concern as a noneconomic buying criterion. Journal of Marketing 58, 119.

[9] Barnes, J.H., 1982. Recycling: a problem in reverse logistics. Journal of Macro-marketing 2 (2), 31-37.

[10] Pohlen, T.L., Farris, M.T., 1992. Reverse logistics in plastics recycling. International Journal of Physical Distribution \& Logistics Management 22 (7), 35-47.

[11] Sarkis, J., 1995a. Manufacturing strategy and environmental consciousness. Technovation 15 (2), 7997. Sarkis, J., 1995b. Supply chain management and environmentally conscious design and manufacturing. International Journal of Environmentally Conscious Design and Manufacturing 4 (2), 43-52.

[12] Seuring, S. and Muller, M. (2008). From a literature review to a conceptual framework for sustainable supply chain management. Journal of Cleaner Production, 16(1699-1710).

[13] Cruz, J.M., Matsypura, D., 2009. Supply chain networks with corporate social responsibility through integrated environmental decision-making. International Journal of Production Research 47 (3), $621-648$.

[14] Young, A., Kielkiewicz-Young., A., 2001. Sustainable supply network management. Corporate Environmental Strategy 8 (3), 260-268.

[15] Kovacs, G., 2004. Framing a demand network for sustainability. Progress in Industrial Ecology: an International Journal 1 (4), 397-410.
[16] Sharfman, M., Shaft, T., Anex, R., 2009. The road to cooperative supply-chain environmental management: trust and uncertainty among proactive firms. Business Strategy and the Environment 18 (1), 113 .

[17] Min, H., Galle, W.P., 1997. Green purchasing strategies: trends and implications. The Journal of Supply Chain Management 33 (3), 10-17

[18] Günther, E., Scheibe, L., 2006. The hurdle analysis. A self-evaluation tool for municipalities to identify, analyse and overcome hurdles to green procurement. Corporate Social Responsibility and Environmental Management, 13(2), 61-77.

[19] Murphy, P.R., Poist, R.F., 2000. Green logistics strategies: an analysis of usage patterns Transportation Journal 40 (2), 5-16.

[20] Gonzalez-Benito,J, Gonzalez-Benito,O - 2006. The role of stakeholder pressure and managerial values in the implementation of environmental logistics practices. International Journal of Production Research 44 (7), $1353-1373$

[21] Bai, C., Sarkis, J., 2010a. Integrating sustainability into supplier selection with grey system and rough set methodologies. International Journal of Production Economics 124 (1), 252-264.

[22] Frota Neto J., Bloemhof-Ruwaard, J., Van Nunen, J., Van Heck, E., (2008) Designing and evaluating sustainable logistics networks, International Journal of Production Economics, Vol. 111, pp.195-208.

[23] ADEME - REPORT of FFSA GENERAL ASSEMBLY REPORT 2012

[24] Cohon, J. (1978). Multiobjective programming and planning. Academic Press, New York.

[25] Brent, A. C. and Visser, J. K. (2005). "An environmental performance resource impact indicator for life cycle management in the manufacturing industry." Journal of Cleaner Production 13(6): 557-565.

[26] Siracusa G., L. R. A. D., Sterlini S.E. (2004). "A new methodology to calculate the environnemental protection index. A case study applied to a company producing composite materials." Journal of Environmental Management 73: 275--284.

[27] Scherpereel, C., van Koppen, C. S. A. and Heering, G. B. F. (2001). Selecting Environmental Performance Indicators." Greener Management International(33): 97.

[28] Tsoulfas, G. T. and Pappis, C. P. (2008). "A model for supply chains environmental performance analysis and decision making." Journal of Cleaner Production 16(15): 1647-1657.

[29] Saling P., Kicherer A., Dittrich-Krämer B., Wittlinger R., Zombik W., Schmidt I. and al (2002). "Eco-efficience analysis by BASF : the method." The International Journal of Life Cycle Assessment 7(4) 203-218.

[30] Soytas, U. and Sari, R. (2009). "Energy consumption, economic growth, and carbon emissions: Challenges faced by an EU candidate member." Ecological Economics 68(6): 1667-1675. 
[31] Rizet and Keïta, 2005 , "Chaînes logistiques et consommation d'énergie : cas du yaourt et du jean » In Inrets-Dest (ed.).

[32] Cholette and Venkat, 2009, "The energy and carbon intensity of wine distribution: A study of logistical options for delivering wine to consumers." Journal of Cleaner Production 17(16): 1401-1413.

[33] ADEME (2007). Guide des facteurs d'émissions Report: Mission interministérielle de l'Effet de Serre.

[34] Lee Schipper, Maria Cordeiro, Wei-Shiuen NG, Measuring the Carbon Dioxide Impacts of Urban Transport Projects in Developing Countries, November 15 th , 2007.

[35] Aikens C.H. Facility Location Models for Distribution planning. European Journal of Operational Research 22, 1985, pp 263-279.

[36] Kaufman L, Eede M.V, Hansen P. A Plant and Warehouse Location Problem. Operational Research Quarterly 28, pp. 547-554, 1977.
[37] Tcha D, Lee B (1984) A branch and bound algorithm for the multi-level uncapacitated facility location problem. Eur J Oper Res 18:35-43

[38] El hassani.H,Benkachcha.S Benhra. J « using genetic algorithm in multiobjective optimization in logistics under environmental considerations(CO2 emission)", Utilisation des algorithmes génétiques (AG) dans l'Optimisation multi-objectif en logistique avec prise en compte de l'aspect environnemental (émissions du CO2), Colloque international LOGISTIQUA 5éme Edition - EMI - RABAT -24\&25mai2012.

[39] Melachrinoudis E, Min H, Wu X. A Multiobjective Model for The Dynamic Location of Landfills. Location Science, Vol 3, $\mathrm{N}^{\circ} 3$, pp 143-166, 1995.

[40] Current J, Ratick S. A model to Assess Risk, Equity and Efficiency in Facility Location and Transportation of Hazardous Materials. Location Science, Vol 3, N³, pp 187-201, 1995

[41] Current J, Daskin M, Schilling D. Discrete Network Location Models. In "Facility Location Theory: Applications and Methods". Drezner Z, Hamacher H.W. Springer Verlag, 2001. 